\title{
Re-Adjustable Male Slings
}

\author{
Wilhelm A. Hübner ${ }^{1}$, Nicolai A. Hübner ${ }^{2}$ \\ ${ }^{1}$ Department of Urology, Weinviertelklinikum, Austria \\ ${ }^{2}$ Karl Landsteiner Institut zur Erforschung der Funktionsstörungen und Tumore des Harntrakts, \\ Korneuburg, Austria \\ Email:w.huebner@yahoo.com,nicolai.huebner@gmx.at
}

Received February 5, 2013; revised March 7, 2013; accepted March 16, 2013

Copyright (C) 2013 Wilhelm A. Hübner, Nicolai A. Hübner. This is an open access article distributed under the Creative Commons Attribution License, which permits unrestricted use, distribution, and reproduction in any medium, provided the original work is properly cited.

\begin{abstract}
Re-adjustable male slings are well established and should be offered to incontinent men with mild, moderate or severe incontinence. However, they should be able to interrupt their stream. Solely the slight increase of the urethral resistance (10 - $15 \mathrm{cmH} 20)$ supporting the smooth muscle component will provide continence for such patients. Argus, Remeex and Atoms allow exactly setting the urethral resistance to a level, which will provide continence thus avoiding obstructive voiding. Implantation may be carried out retropubically (Remeex), via a transobturator route (Atoms) or alternatively (Argus). The success rates after more than one-year follow-up come up to $84 \%$. Intraoperative bladder perforations may occur in $6 \%-11 \%$, late complications are infections possibly leading to explantation in $8 \%-12 \%$. Postoperative perineal pain and/or numbness may be present.
\end{abstract}

Keywords: Re-Adjustable; Adjustable; Male Sling; Argus; Reemex; Atoms; Postprostatectomy-Incontinence

\section{Introduction}

This overview is based upon the most recent and relevant publications found through Pubmed and MEDLINE research using the terms "(re)adjustable male slings, post prostatectomy incontinence, male urinary incontinence and male sling" as well as our own experience of 555 surgeries for male incontinence between 2004 und 2011 including all 3 types of re-adjustable male slings (rAMS), available in Europe (Argus, ATOMS, Reemex).

Numerous suburethral slings for the treatment of male urinary incontinence (MUI) have been described in the past, in fact even a re-adjustable sling has been shown by Kaufmann already back in 1972 [1,2]. However, time was not ready for wide application then.

Due to increasing numbers of radical prostatectomies we today overlook larger homogenous cohorts of incontinent men, which lead to better understanding of the different mechanism of MUI. Thus, suburethral slings and re-adjustable slings (rAMS) in particular have regained interest. The 3 adjustable male slingsystems available in Europe will be described and discussed.

\section{Theoretic Background}

Several components may contribute to function and dys- function of urinary control after RPE [3-6]. The therapeutic approach of rAMS is based upon the concept of Dorschner and co-workers [7]. This includes an internal sphincter at the bladder neck, and an external Raptussphinkter urethrae, which is mainly responsible for continence. However, this external sphincter is sub-divided into a functionally smooth muscle component (M.sphincter urethrae glaber) and a striated component (M.sphincter urethrae transversatorius). While the smooth muscle component - capable of long-term contraction-is responsible for the resting (baseline) continence, the striated sphincter reacts on sudden high pressure rises (stress continence). It is well understood, that during RPE only the enervation of smooth muscle component with in the neuro-vascular bundle will be compromised, while the N.pudendus innervating the striated sphincter remains unchallenged.

This corresponds well to the clinical finding, that most patients are able to interrupt their stream, but still may be significantly incontinent. Solely the slight increase of the urethral resistance $(10-15 \mathrm{cmH} 20)$, representing a support of the smooth muscle component, will provide continence for such patients. rAMS allow to exactly set the urethral resistance to a level, that provide continence thus avoiding obstructive voiding [8-10]. 


\section{Argus}

The argus sling is composed of a radiopaque silicone cushion for soft compression of the bulbar urethra. This cushion is attached to silicone columns, which are made up from multiple conical elements, which allow precise adjustment of the tension with the help of the silicon washers (Figure 1).

\subsection{Surgical Technique}

For implantation a 5 to $8 \mathrm{~cm}$ longitudinal perineal incision is carried out after placement of a foley catheter. The subcutaneous tissue is divided and the bulbospongiosus muscle is prepared. With the intact muscle covering the bulbar urethra the crura are freed on both sides of the bulbo-cavernosus muscle to show the triangular area between crus and muscle. A horizontal incision is made just above the symphysis (optionally two $3 \mathrm{~cm}$ incisions), the rectus-fascia is freed bilaterally approximately $3 \mathrm{~cm}$ off the midline. The implantation needle is brought in from bellow entering the trianglular space between crus and bulbo-spongiosus muscle. The urethra is protected with the tip of the contralateral index finger. The needle is then passed through the pelvic floor and directed later-
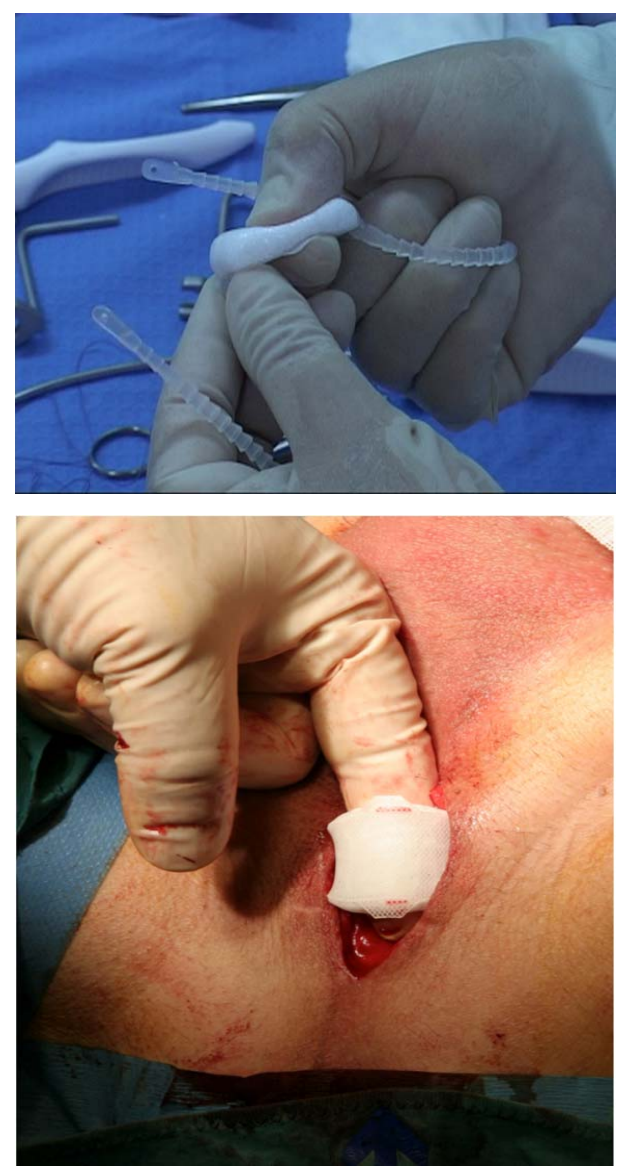

Figure 1. ARGUS adjustable male sling. ally for $15 \mathrm{~mm}$ an then straight upward in close contact with the pubic bone. The sling is now attached to the needle and pulled up to the suprapubic region. The silicon washers are pulled over the column, the excess end is crossed over the midline and placed in the subcutaneous tissue. The silicone cushion is supposed to softly support the bulbar urethra. The tension applied to the urethra should be chosen according to the retrograde leak point pressure (see below).

The argus sling can also be placed in a transobturator approach, in which case typically in $15 \mathrm{~mm}$ incision will be made above the obturator foramen about $2 \mathrm{~cm}$ below insertion of the adductor longus tendinon. A helical insertion needle is provided, which can be passed through the obturator foramen to be retrieved from behind the ischiacal pubic bone from the perineal incision. Again the contra-lateral index finger will protect urethra in this phase. Accordingly, the silicone columns are attached to the implantation needle and pulled through bilaterally. Washers are applied to the column; the excess ends are placed in the subcutaneous fatty tissue towards the suprapubic region.

\subsection{Measuring the Retrograde Leak Point Pressure}

To establish the retrograde leak point pressure (rLPP) a rigid cystoscopy sheath or a foley catheter may be used. A meter stick is attached to an infusion stand with the zero level corresponding to the symphysis and infusion bottle is connected to the foley. The bottle is lowered until the dripping stops. The upper level of the fluid in the bottle represents the rLPP. For incontinent men this pressure will usually be within the range of $15-30$ $\mathrm{cmH} 20$. That goal is to place the sling in a way, that the rLPP will be 10 - $15 \mathrm{~m}$ higher than previously without the sling, however, not exceeding $40 \mathrm{cmH} 20$. After such placement a finger still can easily be placed between urethra and the sling.

\section{Reemex}

The reemex sling consists of a polypropylene mesh with bilateral longitudinal silicone fortifications. The mesh is connected to monofilament traction threads, which will be connected to the so-called "Varitensor". This allows for continuous adjustment of the threads (Figure 2).

\section{Surgical Technique}

Implantation of a reemex sling widely follows the technique of the argus classic approach. However not silicone columns, yet the monofilament traction threads are attached to the implantation needle and brought up to the suprapubic region. These are fixed to the "Varitensor" 


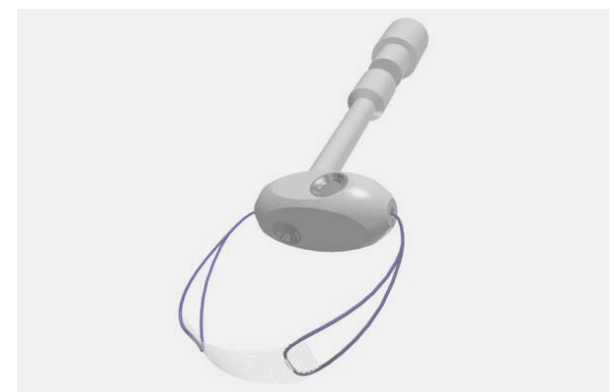

Figure 2. Remmex system.

which allows shortening of the system using a screwdriver-type instrument in order to increase the urethral support. Similar as with the argus sling the tension of the reemex sling maybe adjusted intraoperatively to achieve the desired LPP, however the screw driver may as well be left in place, sticking up outside the wound overnight to allow adjustment on postoperative day 1 with the patient in an upright position as described in the original publication.

\section{Atoms}

The ATOMS sling consists of an inflatable silicone pad with two attached polypropylene mesh arms. The free arms of these meshes maybe fixed to the cushion with the help of preplaced monofilament threads. The pad may be filled with saline through tubing that is attached to a port-a-cath system (Figure 3).

\section{Surgical Technique}

Similar as with the systems shown above a perineal incision is made which however needs to be at least $10 \mathrm{~cm}$ long. Again the M bulbo-spongiosus is freed, in difference to other transobturator approaches the helical needle is inserted in an outside - in fashion through the same incision. The arms are brought to the obturator foramen and reattached to the sling with the preplaced sutures.

The tubing is then brought up to the suprapubic region and the port-a-cath is placed subcutaneously.

\section{Results of rAMS}

Depending on correct indications, success rates of up to $84 \%$ after a follow up of 2 years may be achieved [ 8 , 11-15]. In a recent study even a dry rate of $79 \%$ was reported after argus implantation in a cohort of patients with moderate to severe incontinence [10]. Reportedly up to $38.6 \%$ will require postoperative adjustment. Intraoperative bladder perforations may occur in up to $11 \%$, however, when recognized intraoperatively simple reinsertion of the sling will leave the patient without late complications $[10-12,16]$. Temporary perineal pain may occur postoperatively in up to $15 \%$, sling explantation

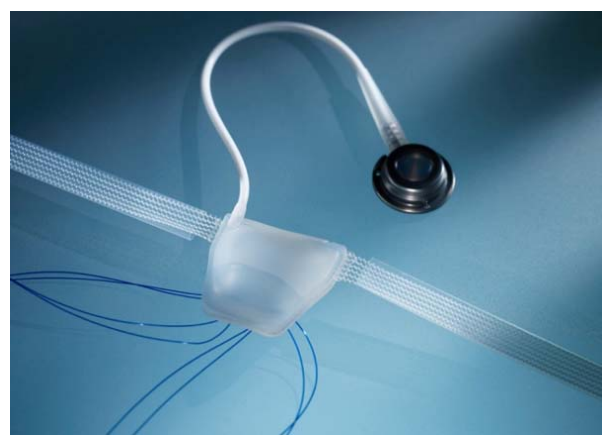

Figure 3. Atoms inflatable male sling.

due to arrosion or infection will be necessary in $8 \%$ $12 \%[10-14,16]$. In a single centre study comparably poor results were achieved with a first generation sling, in fact the authors admit that inter alia the surgical technique needed improvement [17]. According to our own experience as well as to reports at respective Conventions ATOMS seems to achieve similar results, in a recently published series after a mean follow-up of 16.9 months a success rate of $84.2 \%$ was presented (of those $60.5 \%$ dry). However perineal pain was seen in 20 of 38 patients, yet resolved spontaneously [18]. The results are summarized in Table 1.

\section{Discussion}

First publications of larger series of rAMS date back to 2004 Sousa and 2006 Romano $[8,11,12]$. Accordingly records of Argus and Reemex slings can be classified as reliable and equivalent. Today re-adjustable male slings are well established.

Compression of the bulbar urethra in fact carries the risk of obstruction and even retention. Therefore it is necessary to limit such compression to the lowest level which will still provide continence. Based upon the mechanism described by Dorschner et al. [7] only a minimal elevation of the urethral resistance, representing the smooth muscle component contributing to continence, will restore urinary control [8-10]. Stress continence will still be provided by the well functioning striated sphincter components including the pelvic floor. rAMS allow to apply such compression to the urethra in order to achieve the goal of baseline continence with- out causing obstruction. Thus, retention has not shown to be a problem with rAMS. On the other hand, readjust- ment of the slings even after months or years in order to react on changing demands or functional parameters of a specific patient has shown to be useful and successful $[8-12,16]$.

The success rates described in publications with more than one year follow-up come up to $84 \%$, even in a cohort of patients with moderate to severe incontinence dry-rates of nearly $80 \%$ can be achieved $[8-12,16]$.

Possible complications are late infections possibly lead- 
Table 1. Results of different adjustable slings.

\begin{tabular}{ccccc}
\hline Author & Implant & $\begin{array}{c}\text { Dry-rate/ } \\
\text { Success-rate }\end{array}$ & $\mathrm{n}$ & Follow-up \\
\hline $\begin{array}{c}\text { Romano SV } \\
\text { et al. } \text { [9] } \\
\begin{array}{c}\text { Hübner W } \\
\text { et al. }{ }^{*}[10]\end{array}\end{array}$ & Argus & $66 \% / 79 \%$ & 48 & 45 months \\
$\begin{array}{c}\text { Sousa-Escandon A } \\
\text { et al. }[11,12]\end{array}$ & Reemex & $64.7 \% / 84.3 \%$ & 51 & 32 months \\
$\begin{array}{c}\text { Seweryn J } \\
\text { et al. }[18]\end{array}$ & Atoms & $50 \% / 84.2 \%$ & 38 & 16.9 months \\
\hline
\end{tabular}

${ }^{*}$ No mild incontinence cases included.

ing to explantation in $8 \%-12 \%$. Postoperative perineal pain and/or numbness also need to be mentioned, although hardly found in publications. In fact, based upon information gained of several discussions at international meetings these symptoms will resolve in 4 to 8 weeks but have also been reasoned for explantation of devices placed via a transobturator route.

rAMS should be offered to incontinent men with mild to moderate or even severe incontinence who do have a well functioning pelvic floor thus enabling interruption of the stream. The characteristics of rAMS are high dry rates in opposition to an explantation rate of $8 \%-16 \%$. The group described as "improved by $50 \%$ or more" is less frequently found after rAMS placement. Poor indications are patients unable to interrupt their stream or patients with detrusor acontractility.

\section{REFERENCES}

[1] J. J. Kaufman, "Urethral Compression Operations for Treatment of Post-Prostatectomy Incontinence," Journal of Urology, Vol. 110, No. 1, 1973, pp. 93-96.

[2] J. Berry, "New Procedure for Correction of Urinary Incontinence: A Preliminary Report," Journal of Urology, Vol. 85, 1961, pp. 771-775.

[3] M. Porena, E. Mearini, L. Mearini, A. VIanello and A. Giannantoni, "Voiding Dysfunction after Radical Retropubic Prostatectomy: More than External Urethral Sphincter Deficiency," European Urology, Vol. 52, No. 1, 2007, pp. 38-45. doi:10.1016/j.eururo.2007.03.051

[4] P. Rehder and C. Gozzi, "Transobturator Sling Suspension for Male Urinary Incontinence Including Post-Radical Prostatectomy," European Urology, Vol. 52, 2007, pp. 860-866. doi:10.1016/j.eururo.2007.01.110

[5] P. Hammerer and H. Huland, "Urodynamic Evaluation of Changes in Urinary Contol after Radical Retropubic Prostatectomy," Journal of Urology, Vol. 157, No. 1, 1997, pp. 233-236. doi:10.1016/S0022-5347(01)65334-5

[6] K. R. Loughlin and M. M. Prasad, "Post-Prostatectomy Urinary Incontinence: A Confluence of 3 Factors," Journal of Urology, Vol. 183, No. 3, 2010, pp. 871-877. doi:10.1016/j.juro.2009.11.011

[7] W. Dorschner, J. U. Stolzenburg and J. Neuhaus, "Anatomic Principals of Urinary Incontinence," Urologe A, Vol.
40, No. 3, 2001, pp. 223-233. doi: $10.1007 / \mathrm{s} 001200050466$

[8] S. V. Romano, S. E. Metrebian, F. Vaz, V. Muller, C. A. D'ancona, E. A. de Souza and F. Nakamura, "An Adjustable Male Sling for Treating Urinary Incontinence after Prostatectomy: A Phase III Multicentre Trial," BJUI International, Vol. 97, No. 3, 2006, pp. 533-539. doi:10.1111/j.1464-410X.2006.06002.x

[9] S. V. Romano, S. E. Metrebian, F. Vaz, V. Muller, C. A. D'ancona, E. A. de Souza and F. Nakamura, "Long-Term Results of a Phase III Multicentre Trial of the Adjustable Male Sling for Treating Urinary Incontinence after Prostatectomy: Minimum 3 Years," Actas Urológicas Españolas, Vol. 33, No. 3, 2009, pp. 309-314.

[10] W. A. Hübner, H. Gallistl, M. Rutkowski and E. R. Huber, "Adjustable Bulbourethral Male Sling: Experience after 101 Cases of Moderate-to-Severe Male Stress Urinary Incontinence," BJUI International, Vol. 107, No. 5, 2011, pp. 777-782. doi:10.1111/j.1464-410X.2010.09619.x

[11] A. Sousa-Escandon, J. I. Rodriguez Gomez, C. Uribarri Gonzalez and A. Marques Queimadelos, "Externally Readjustable Sling for Treatment of Male Stress Urinary Incontinence: Points of Technique and Preliminary Results," Journal of Endourology, Vol. 18, No. 1, 2004, pp. 113-118.

[12] A. Sousa-Escandon, J. Cabrera, F. Mantovani, et al., "Adjustable Suburethral Sling (Male Remeex System) in the Treatment of Male Stress Urinary Incontinence: A Multicentric European Study," European Urology, Vol. 52, No. 5, 2007, pp. 1473-1479. doi:10.1016/j.eururo.2007.05.017

[13] H. Gallistl, O. Schlarp and W. A. Hübner, “Argus: Eine neue Adjustierbare Schlinge für die Therapie von Prostatektomieinkontinez," Urologe A (German), Vol. 45, 2006, p. 43.

[14] H. Gallistl, E. Huber and W. A. Hübner, "ARGUS: A New Adjustable Sling in the Low Invasive Treatment of Post-Prostatectomy Incontinence," European Urology, Vol. 7, 2008, p. 88. doi:10.1016/S1569-9056(08)60073-1

[15] S. V. Romano, W. A. Hübner, F. Trigo Rocha, et al., "The Adjustable Male Sling Can Be Successfully Implanted by Transobturator Approach for Treating PostProstatectomy Urinary Incontinence, Surgical Technique and Early Results of a Multicentre Trial," ICS, 2009.

[16] A. Sousa-Escandon, J. Cabrera, F. Mantovani, et al., "Adjustable Suburethral Sling (Male Remeex System) in the Treatment of Male Stress Urinary Incontinence: A Multicentric European study," European Urology, Vol. 52, No. 5, 2007, pp. 1473-1479. doi:10.1016/j.eururo.2007.05.017

[17] O. Dalpiaz, H. J. Knopf, S. Orth, K. Griese, S. Aboulsorour and M. Truss, "Mid-Term Complications after Placement of the Male Adjustable Suburethral Sling: A Single Center Experience," Journal of Urology, Vol. 186, No. 2, 2011, pp. 604-609. doi:10.1016/j.juro.2011.03.131

[18] J. Seweryn, W. Bauer, A. Ponholzer and P. Schramek, "Initial Experience and Results with a New Adjustable Transobturator Male System for the Treatment of Stress Urinary Incontinence," Journal of Urology, Vol. 187, No. 3, 2012, pp. 956-961. doi:10.1016/j.juro.2011.10.138 